\title{
Correction to: Identification of quantitative trait locus and prediction of candidate genes for grain mineral concentration in maize across multiple environments
}

\author{
Huaduo Zhang • Jingxian Liu • Tiantian Jin - Yaqun Huang • \\ Jingtang Chen $\cdot$ Liying Zhu $\cdot$ Yongfeng Zhao $\cdot$ Jinjie Guo
}

Published online: 15 March 2018

(C) Springer Science+Business Media B.V., part of Springer Nature 2018

Correction to: Euphytica (2017) 213:90

https://doi.org/10.1007/s10681-017-1875-7

By mistake this article had a note indicating that the article is part of the following topical collection:

"This article is part of the Topical Collection on Plant Breeding: the Art of Bringing Science to Life.
Highlights of the 20th EUCARPIA General Congress, Zurich, Switzerland, 29 August-1 September 2016 Edited by Roland Kölliker, Richard G. F. Visser, Achim Walter \& Beat Boller"

The article however is not part of this collection and should be seen as such by the reader. 